\title{
Question-Negotiation and Information Seeking in Libraries: A Timeless Topic in a Timeless Article
}

\section{David A. Tyckoson}

It has been almost 50 years since Robert Taylor published this classic article in $C \mathcal{E} R L$; yet much of what that article discussed is as fresh today as it was back then. ${ }^{1}$ As Taylor wrote, "Without doubt, the negotiation of reference questions is one of the most complex acts of human communication" (180). Of course, that is what makes it a classic-it has enduring themes that have prevailed over time.

Taylor's article is still being frequently cited - and this is by no means the first time that it has been identified as a classic. In a 2009 article on the most highly cited articles in Library and Information Science, the authors used the Web of Science database to analyze all of the more than 82,000 papers in the Web of Science subject category of Information Science and Library Science (ISLS). ${ }^{2}$ In that universe of source material, Taylor was found to be the 17th most cited ISLS article. Given the tendency of Web of Science to focus more on the hard sciences than other disciplines, most of the top articles were either information retrieval or computer science papers. In fact, Taylor is the only one in the top 82 that used any variation of the word library in its title. Based on that Web of Science data, Taylor's paper is the single most cited library science journal article of all time.

My own similar analysis of the Taylor article in Fall 2014 found 364 citations in the Web of Science - and more than 1,000 in Google Scholar. Interestingly, the rate of citation per year has risen over time rather than declined. There were more citations to Taylor in 2011 than in any other single year-and more citations in the last decade (2005-2014) than in any single prior decade. Very few articles in our discipline have either the quantity or the longevity of citation relevancy as Taylor's paper. This is clear evidence that Taylor's work remains relevant.

The methodology that Taylor used was very innovative for its time. Instead of taking surveys, Taylor conducted in-person interviews with researchers about the processes that they used to find information in real life. He also had a class of undergraduate students log their own process of searching for information while working on a project. This approach focused on actual behaviors of users (and librarians) and anticipated many of the anthropological and ethnographic research studies that are being conducted today.

Based on the information obtained from those interviews and research logs, Taylor created a hierarchy of levels of understanding that can be applied to any research query. These include the actual, unexpressed need (visceral need); the conscious, within-brain description of the need (conscious need); the formal statement of that need (formalized

David A. Tyckoson is Associate Dean at California State University, Fresno; e-mail: davety@csufresno.edu. (C) 2015 David A. Tyckoson, Attribution-NonCommercial (http://creativecommons.org/licenses/by-nc/3.0/) CC BY-NC. 
need); and the question as presented to the information system (the compromised need). His description of how questions evolve from the visceral to the compromised provides insight into how people's queries evolve over time as they approach their information needs. This was one of the first papers to recognize that search questions do not begin as fully formed concepts - and that the questions need to be adapted to fit the constructs of the existing information systems.

Because of its then-new approach to studying how people ask for help in finding information, this paper has been a staple reading in most library school reference courses. It was included in the bibliography of every edition of Bill Katz's classic textbook on reference, from the first in 1969 through the sixth in $1992 .{ }^{3}$ Similarly, it has been cited in every one of Richard Bopp and Linda Smith's reference textbooks from the first in 1995 through the 4 th in $2011 .{ }^{4}$ M. Kathleen Kern, former president of the Reference and User Services Association (RUSA) and author of the chapter in the Bopp and Smith text on the "reference interview," is planning to continue to cite Taylor in the 5th edition scheduled for publication this year. By virtue of its inclusion in those two standard textbooks, it is safe to say that every practicing reference librarian today will have had the opportunity to encounter Taylor's article at some point during his or her training.

Last year, Yu-Wei Chang published an article discussing the influence of Taylor's paper, making this one of the few library science articles - and maybe the only oneto have also been the sole subject of another library science article. ${ }^{5}$ Chang used the Web of Science to study how this article has been cited over time. Most of the citing articles fell into expected categories, including Information Retrieval (40\% of citations), Information Behavior (30\% of citations), and Reference Services ( $20 \%$ of citations). However, she also found that Taylor has been cited in papers from a wide variety of other disciplines, including Computer Science, Medical Education, Management, and Women's Studies. The specific concepts those authors cited within Taylor's article also vary widely, with the most common being the Four Levels of Information Need (32\%), Question Negotiation (21\%), and Other Concepts Relating to Information Needs (18\%). It is interesting but not surprising that Taylor's paper is still receiving this type of star treatment, since it is, according Kern, "Absolutely a seminal work."

Thirty years ago, this paper was already being recognized as a classic by the Institute for Scientific Information, publishers of Web of Science. From 1977 to 1993, Current Contents published a series of essays and commentaries on the most cited articles in all disciplines, which they called Citation Classics. Taylor's paper was chosen as the November 25, 1985, Citation Classic, with Robert Taylor himself writing the analysis. ${ }^{6}$ That an article from library science even made the list of papers to be reviewed is remarkable, given the relatively small size of our field in comparison to the sciences and social sciences. That it was one of the 500 most cited papers from any subject field is extraordinary. Very little of the research done in libraries ever generates such a wide scope of interest as this one.

Of course, for an article to be cited that frequently, it must have had something important to say. And indeed, Taylor says some very important things. He was one of the first to systematically study how users formulate questions and how those questions get translated into the language of the information system. By studying users and the librarians who help them, he was able to identify his now-famous four levels of information need: visceral, conscious, formalized, and compromised. He also studied how librarians take these needs-especially the compromised need-and adapt them to the existing information systems. Taylor intentionally selected users and librarians in special library environments, where information needs are often complex and where the language of the discipline is much more structured. By using fields in which the language of the literature and of the questions would be the most structured-includ- 
ing engineering, science, medicine, and law - he was able to demonstrate many of the problems encountered when communicating about information needs. Those problems would be amplified in disciplines where the language is less precise.

Throughout the article, Taylor talks about the interface between the human with an information need and the information system that is expected to fill that need. We must remember that, in Taylor's day, the information system consisted of print sources - books, journals, reports, and documents - that had to be consulted in person in the library. And the search tools of the time-card catalogs and large sets of printed indexes - also had to be consulted in person in the library, which required a considerable investment in time and effort by the user. The library played a much more central role in organizing information for its community at those times, since by necessity the user had to be in the library to get the information. And yet, even working in the constraints of the information systems of his time, Taylor anticipates some of the communication tools that we use today. His description of information "arriving" by letter or telephone could apply equally as well to e-mail, chat, and instant messaging today.

Today, of course, information is available and accessible anywhere at any time. Users are no longer required to come into the physical library to find information - they can get it whenever they need it wherever they are located. New tools such as Wikipedia and Google have transformed the sources that we use and the ways that we search those sources. In many ways, the issues Taylor discusses are echoed in today's web usability studies and natural language searching techniques. Despite the fact that today's users get immediate search results, they still have difficulty formulating their search queries. The four levels of understanding of the information need that Taylor identified almost fifty years ago remain important factors in searching today. Users still have problems finding information - and reference librarians still need to communicate with those users to figure out exactly what they want.

This is perhaps Taylor's greatest contribution-refocusing the conversation about information seeking away from the tools and the sources and toward the people who use them. Today's tools and information sources are very different from those that Taylor would have seen or even imagined. And tomorrow's tools and sources will be as different from those we use today as ours are from those of 1968. Yet we will still help users formulate queries and will still engage Taylor's stages of query formation and negotiation, from the visceral, not really understood initial concept, through the formal stage, and into the compromised stage that matches expected outputs from our information systems.

While libraries are certainly about collections, tools, and services, mostly they are about people. Technologies and sources change daily, but the constant factor in libraries will always be people. People will always comprise our community of users, and people will always be the library staff assisting those users. Back in an era when libraries were measured primarily by the numbers of volumes in their collections, Taylor's paper brought us back into thinking about the people that we serve and how we can best help them. It is Taylor's human focus that has made this paper a classic-and that will probably continue to define it as a classic well into the future.

\section{Notes}

1. Robert S. Taylor, "Question-Negotiation and Information Seeking in Libraries," College \& Research Libraries 29, no. 3 (1968): 178-94.

2. Jonathan M. Levitt and Mike Thielwall, "The Most Highly Cited Library and Information Science Articles: Interdisciplinarity, First Authors and Citation Patterns," Scientometrics 78 (2009): 45-67. 
3. William A. Katz, Introduction to Reference Work. 2 vols. (New York: McGraw-Hill, 1969); William A. Katz, Introduction to Reference Work. 6th ed., 2 vols. (New York: McGraw-Hill, 1992).

4. Reference and Information Services: An Introduction, eds. Richard E. Bopp and Linda C. Smith (Santa Barbara, Calif.: ABC-CLIO, 1995); Reference and Information Services: An Introduction, eds. Richard E. Bopp and Linda C. Smith. 4th ed. (Santa Barbara, Calif.: ABC-CLIO, 2011).

5. Yu-Wei Chang, "The Influence of Taylor's Paper, Question-Negotiation and Information Seeking in Libraries," Information Processing and Management 49 (2013): 983-94.

6. Robert S. Taylor, "This Week's Citation Classic," Current Contents: Social and Behavioral Sciences 47 (Nov. 25, 1985): 24. 